\title{
Effectiveness of Audio-Visuals in Enhancing Understanding of Circulatory System
}

\author{
Prosper Apaliya Agangba ${ }^{1}$, Mark Wesono Ayiwah ${ }^{2 *}$ \\ ${ }^{1}$ Awe Senior/Technical High School, P.O. Box 105, Navrongo, Upper East Region, Ghana. \\ ${ }^{2}$ St Vincent College of Education, P.O. Box 184, Yendi, Northern Region, Ghana.
}

\begin{abstract}
The objective for this study was to determine the effectiveness of audio-visual method of teaching over traditionally designed instruction on second year students of Awe Senior High Technical School in circulatory system. Two (2) research questions and two (2) null hypotheses were formulated to serve as guide for this study. Samples of two intact technical classes were placed into experimental and control groups. The study made use of a standardized achievement test items and a structured questionnaire as the instruments for data collection, the scores obtained were analysed using the t-test statistical method. Quasi-experimental non-randomised design involving the pre-test and post-test was employed for the purpose of this study. The result obtained in this study showed that out of the null hypotheses formulated and tested at $95 \%$ level of significance, one was rejected while the other was accepted. The rejection was attributed to the use of audio-visuals. The findings revealed that the use of audio-visuals in teaching was most effective way of improving student's performance in the teaching and learning of circulatory system in Integrated Science.
\end{abstract}

Keywords: Circulatory System, Audio-Visuals learning, achievement test

DOI: $10.7176 / \mathrm{JEP} / 10-3-20$

\subsection{Introduction}

It is very clear that the world that we live in is constantly being moved by the progress being made in science and technology especially in the developed countries of the world. A strong science and technology knowledge base therefore constitutes the currency for social and economic transformation of nations. Nation states that have developed have utilised the opportunities offered by the current phenomenal increase in science and technology especially information and communication technology, biochemistry and material science. Such nations have scaled the poverty barrier and moved into the club of rich countries. Some of these countries including Singapore, South Korea and Malaysia, which in the 60 s were at the same developmental level as Ghana have witnessed improvement in their economies through the development and application of science and technology (Anamuah-Mensah, 2004).

Since Ghana want to develop rapidly then there is the need for science, mathematics and technology to become the pivot of their education starting from the early childhood.

The recent education reform buttress this point as it was stated clearly in the executive summary of the President's Committee on Review of Educational Reforms in Ghana October 2002, the key to the future socioeconomic development of Ghana lies in the development of a large number of scientists, engineers, technologists, technicians and draftsmen to bring about technological innovations. To achieve this it is then imperative that science and science education must be given the number one priority.

Science is defined as a body of knowledge gained by observation and experiment (Otto \& Towle, 1985). Science can then be explained simply as the search for explanation of what we observe in nature and knowledge we have discovered. However students perceived science to be so strange and too difficult and this perception cuts across all levels of education where science is taught. Due to this perception about science, student at every level of the education ladder try to avoid it when given the opportunity (Graham, 1976).

At the secondary stage the study of natural sciences is receiving and increasing emphasis day by day. The browning number of the students offering science group at high of higher secondary stage, and inclusion of 
integrated science as a compulsory subject of study justifies its great significance. Perhaps it is due to the impact of technological development taking place in the country and an ever increasing demand of skilled workers for feeding the various industries running or in making all over the country. Obviously such an important subject like science must receive the immediate attention of those entrusted with responsibility of teaching the subject at different levels (Shri \& Badri, 2014).

In the light of responsibility an effort is made through this study to assess the effectiveness of using AudioVisuals aids in enhancing understanding of circulatory system in integrated science at the secondary level to make the teaching really purposive and useful. The importance of natural science have also been realized by the medallion commission in the following words: "An understanding and appreciation of the fundamental principles of the natural and physical science is essential to effective living in the world of today."

The realm of this modern education is to awaken the hidden curiosity and interest of the learner, nourishing his behaviors, attitudes and believes in order to develop basic and essential skills of lifelong learning and ability to think critically and to judge him and others in a more beneficial manner (Samreen et al.2012).

Students should be given confidence to ask, inquire, explore and be creative and initiators. Infect an inquisitive mind is the beginning to lifelong learning that surely leads to success. Before modern education was incorporated students was passive listener and teacher was autonomous body who knows what, when and how of education. But in recent years the superiority is shifted towards students. Use of audio-visual aids is preferred as they are considered as $85 \%$ of whole teaching and learning (Jadal, 2011). They keep the individual learner focused on what is being taught by the teacher in the classroom session.

It is apparent that the stakeholders of education such as Ministry Of Education, Ghana Education Service, Curriculum and Research Development Division (CRDD), Government etc, has the optimal responsibility to find solutions to the problem, the onus also lies on the teacher of the subject who have day to day interaction with students to device means of averting the problem by arousing the interest of the pupils in the subject thus embarking on the research "Effectiveness of audio-visuals in enhancing the understanding of circulatory system".

\subsection{Problem statement}

It has been recognised by various researchers of science curriculum at various levels of education that, "scientific concept taught in abstract terms forces students to resort to rote learning without understanding" (Felder, 1993, p.18). Concepts of human digestion, circulation of blood in mammals, excretion, fertilization in human and flowering plant, flower formation are clear examples. This has led to poor performance of students in the biology aspect of integrated science at the Senior High School level as indicated by the chief examiner report West Africa Examination Council (WAEC, 2011).

Colleague teachers teaching integrated science and as well as integrated science examiners also share this assertion by the WAEC biology chief examiners report on science students' performance.

The WAEC biology chief examiner attributes the low performance to student's failure to properly understand exams questions and providing correct answers. These students' failures can be traced to students' inability to grasp properly the fundamental concepts in science and teachers failure to communicate the fundamental concept via the appropriate method of teaching science, further discussion and analysis of the problem from fellow science teachers and science examiners revealed that major contributing factor is the use of inappropriate method of teaching science by teacher and inadequate classroom facilities.

Most science teachers including myself have adopted various methods of teaching and learning science in the hope of communicating effectively the core ideas and concept of science to the students. Common methods of teaching employed over the years are the traditional or lecture method of teaching, inquiry method, collaborative method etc.

These methods even with the addition of charts and improvised teaching and learning materials are unable to proper explain concepts such as the process of photosynthesis, circulation of blood in mammals, digestion in mammals, transpiration in plant, fertilization process in plant, skeletal system etc. 
To overcome some of the difficulties teachers and students face under this method as suggested by Davis (1993) and Mckeanchie (1994), is to use audio-visuals to enhance presentation and to captivate and sustain students. Also, adopt reasonable and adjustable pace that balances content coverage and student understanding.

\subsection{Purpose of the study}

The research is to find out whether the use of audio-visuals as a teaching method improves the teaching and learning of circulatory system in integrated science amongst students of Awe Senior High/Technical School.

\subsection{Objectives of the study}

1. To determine the knowledge students have about circulatory system in integrated science before the instructional strategies.

2. To compare the performance of students taught circulatory system at post-test using audio-visuals and those taught using traditional method of teaching.

\subsection{Research questions}

In order to ascertain the effectiveness of audio-visuals in understanding circulatory system in the selected Senior High School, the following questions were addressed in the study:

1. What is the knowledge students have about circulatory system in integrated science before the instructional strategies

2. Is there any difference in post-test scores between the experimental group students who learnt with audio-visuals and control group students who learnt with the traditional method of teaching?

\subsection{Research Hypotheses}

In line with the research questions, the following null hypotheses were raised for this study:

1. $H_{\mathrm{j}}$ : There is no significant difference in between both groups (classes) on circulatory system at pretest

$H_{1}$ : There would be significant difference in between both groups (classes) on circulatory system at pretest.

2. $H_{0}$ : There is no significant difference in between both groups (classes) on circulatory system at post-test.

$H_{1}$ : There would be significant difference in between both groups (classes) on circulatory system at post-test.

\subsection{Methodology}

Two groups pretest posttest, quasi-experimental (non-randomized control group) design was used to examine the impact of the performance of students on circulatory system. With two similar technical classes $2 \mathrm{~A} \& 2 \mathrm{~B}$ intact classes in which one was experimental group and the class control group, there was no sub sampling. This meant that all students within sampled classes participated in the research with the exception of students who were absent during the research period.

\subsection{Population of Sample}

The population of the Awe SHTS was one thousand and five (1500) students and had seventy five (75) teachers on the staff. The target population was the second year technical students who offer integrated science in the school and were fifty each in a class.

\subsection{Sample Technique}

Purposive sampling technique was used to select the class for the study. Purposive sampling which is a nonprobability sampling was used because it allowed the researcher to choose the subjects on purpose of study or because they possess the information the researcher needs or they possess specialist knowledge of the research issue, or capacity and willingness to participate in the research (Creswell, 2005). 


\subsection{Sample and Sample Size}

Data gathering is crucial in research, as the data is meant to contribute to a better understanding of a theoretical framework (Bernard, 2002). It then becomes imperative that selecting the manner of obtaining data and from whom the data will be acquired be done with sound judgment, especially since no amount of analysis can make up for improperly collected data (Bernard et al. 1986).

The sample for the study was two intact technical classes which were selected from nine other integrated science classes, which were at different levels (i. e. SHS 1, $2 \&$ 3). Since they were intact classes, the entire subjects were involved in the research. The sample chosen was the second year integrated science students. They were fifty students per class. These classes were chosen because they had been taught a lot of topics and concepts and so were reading wide in order to complete their course. At that stage of their education, different teaching methods had been introduced to them. The sample size of 100 was used to enable the researcher work effectively within the limited period.

\subsection{The study area}

The study was conducted in Awe Senior High/Technical School. The school is located on the outskirts of Navrongo Township. Navrongo is a town in the Kassena/Nankana Municipality of the Upper East Region of Ghana. The Kassena/Nankana Municipality has six (6) government Senior High Schools, two of them are single sex schools and the rest are co-education with one being an integrated school. The Municipality is a savannah area and is characterized by high dryness.

Awe SHTS is rated a ' $C$ ' school according to the Ghana Education Service classification. It offers the following courses: Elective Science, Home Economics, Agriculture, General Arts, Visual Arts and Technical (building construction and wood work). There are nine classes at each level and only two out of the nine classes was considered.

\subsection{Variables for the study}

The independent variable in this study was two (2) weeks teaching instructional programme that was administered to the two classes.

The dependent variable in this study was the student's scores obtained in the traditional method of teaching and the audio-visual method of teaching on the topic circulatory system.

\subsection{Instrumentation}

A close-ended objective test item was the instrument used to collect data on the performance of the students on circulation system at pretest and posttest. The closed ended questions were appropriate for this study since it allowed respondents to choose between options provided by the researcher and have increasingly become popular compared with open-ended questions (smith, 1987).

\subsection{Procedure for Implementation of the Instructional Programme}

The instructional programme was implemented through teacher centered and audio-visual centered. The samples were subjected to different treatment for two weeks each.

The Technical 2A class was given a pretest and taken through lessons on circulation system using teachercentered instructional approach. This was where the teacher transmitted information via the traditional method of teaching or the lecture method with little or no teaching and learning material involved. After using the teachercentered approach for two weeks, a class test (posttest) was conducted to assess the performance of the students on the lesson taught. The class test which consisted of 20 test items of objective questions with multiple answers. The student response was collected, marked and recorded.

The Technical 2B class was also be given a pretest and for two weeks, taught using audio-visuals. This is where the teacher transmits the same information via the audio-visual aids. A set of educational films, pictures, charts displays, videos from a computer through a projector and beamed onto a white screen with the volume 
transmitted through audible speakers. After the two weeks, a class test (posttest) was conducted to assess the performance of the subjects on the lesson taught.

\subsection{Validity of the Instrument}

Validity has been defined by "the extent to which a test measures what it claims to measure" (Gregory, 1992). Any measure can be called as "valid" if it measures what it is supposed to measure.

To ensure test items validity, they were given to a supervisor for thorough examination in order to ensure that they measured the total content area (content validity) of the study. To ensure internal validity, peer reviews by experienced science teachers were employed. Fellow graduate students at the Department of Science Education, University of Education, Winneba were given the items to study it and comment on it.

\subsection{Reliability of the instrument}

Reliability concerns with the extent to which a questionnaire, test or any measurable procedure produces the same results on a repeated trials. That is, it is the consistency of score over time.

To ensure the reliability of the research instrument, a pilot test was carried out on a sample of SHS 2 integrated science students at Navrongo SHS. Data from the pilot test was statistically analyzed and determined the reliability of the test instruments using cronbach alpha reliability coefficients and was calculated to be 0.72 .

\subsection{Data Collection Procedure}

The test items was administered personally by the researcher to the form two integrated science technical classes' students of Awe Senior High/Technical School after seeking permission from the headmaster and the head of department of science.

The mode used for administering the test items was the investigator-administered mode.

This mode of administration ensured $100 \%$ collection of the test item response. Also respondents were not allowed to communicate among themselves to ensure that responses were not affected by other respondent's views. Again for respondents to be candid about their responses they were made aware of the fact that the test was for academic purpose only and that the information they were providing would be kept strictly confidential and that no name was to be written on the test items.

\subsection{Data Analysis}

The data collected was examined for consistency and accuracy by reading through all the responses that were provided by the respondents.

The statistical analysis of the test (pretest and posttest) was carried out first. The descriptive statistics such as means, mean difference, standard deviation, percentages and t-test of both experimental and control groups were computed by computer statistical product service solutions (SPSS) version 20.0 programme. These descriptive statistics were used to summarize the general trends in student performance. The purpose of descriptive statistics is not only to describe the data from the study but also to help find pattern within the data described and to inform inferential statistics as well. Coding schemes were developed to organize the data into meaningful and manageable categories.

The raw data entries were done by the researcher in order to ensure accuracy of entry of the data.

\subsection{RESULTS}

The results and discussion were presented in the order of the research questions and the null hypothesis. The guiding research questions of this study were to determine whether the students of awe senior high school would perform well academically in circulatory system or not when they are taught using audio-visuals.

The primary source for data about circulatory system was academic performance in the pretest and posttest scores for both students instructed by using audio-visuals and traditional teaching method. The student t-test 
analyses of the collected data were performed alongside with the discussion. All of the data from this study were intended to complement one another in order to provide evidence for the interpretation of effect of audio-visuals on the students' understanding of the concept. Findings of the study are discussed in the light of available literature.

\subsection{Presentation of results and findings of the study according to research questions and hypothesis}

\subsubsection{Analysis with respect to Research Question One.}

Research question 1: What is the knowledge students have about circulatory system in integrated science before the instructional strategies?

\section{Students marks at pretest for both control and experiment group}

The tables below were obtained when a 20 test question items on circulatory systems in integrated science was administered two classes (control and experimental).Each mark was given a weight of 5\% which implies that a total score of 20 is $100 \%$. The data contains the raw scores in class intervals of converted percentile marks on a WAEC and GES standard and their corresponding frequencies, and means and standard deviations.

Table 1. Group Frequency distribution of students in control group at pretest

\begin{tabular}{cccc}
\hline $\begin{array}{c}\text { Expected Performance Scale by GES \& } \\
\text { WAEC (Marks \%) }\end{array}$ & Grade & Frequency & Percentage (\%) \\
\hline $0-39$ & F9 & 33 & 66 \\
$40-49$ & E8 & 10 & 20 \\
$50-54$ & D7 & 4 & 8 \\
$55-59$ & C6 & 0 & 0 \\
$60-64$ & C5 & 2 & 4 \\
$65-69$ & C4 & 1 & 2 \\
$70-74$ & B3 & 0 & 0 \\
$75-79$ & B2 & 0 & 0 \\
$80-100$ & A1 & 0 & 0 \\
Total & & $\mathbf{5 0}$ & $\mathbf{1 0 0}$ \\
\hline
\end{tabular}

Source: field data, April 2016

One student had the best grade which was ' $\mathrm{C} 4$ ' thus representing $2 \%$ of the sample. Two (2) students had ' $\mathrm{C} 5$ ' representing $4 \%$, then grade 'D7' with frequency of 4 representing $8 \%$, followed by grade 'E8' with a frequency of 10 representing $20 \%$ and finally grade 'F9' which recorded the highest frequency of 33 representing $66 \%$ thus more than half of the sample failed in the pretest (Table 1). 
Table 2. Students mean value of pretest in control group

\begin{tabular}{lcccl}
\hline & Mean & $\mathrm{N}$ & Std. Deviation & Std. Error \\
\hline Pretest & 33.1 & 50 & 12.813 & 1.8120 \\
\hline
\end{tabular}

\section{Source: field data, April 2016}

Table 2 shows some statistical tendencies of the pretest. The mean gave 33.1 while the standard deviation was 12.813. So the mean score of the test result shows the knowledge the students possess before the use of the traditional method of teaching.

Table 3. Group Frequency distribution of students in experimental group at pretest

\begin{tabular}{llcc}
\hline Marks (\%) & Grade & Frequency & Percentage (\%) \\
\hline $0-39$ & F9 & 38 & 76 \\
$40-49$ & E8 & 9 & 18 \\
$50-54$ & D7 & 1 & 2 \\
$55-59$ & C6 & 0 & 0 \\
$60-64$ & C5 & 1 & 2 \\
$65-69$ & C4 & 1 & 2 \\
$70-74$ & B3 & 0 & 0 \\
$75-79$ & B2 & 0 & 0 \\
$80-100$ & A1 & 0 & 0 \\
Total & & $\mathbf{5 0}$ & $\mathbf{1 0 0}$ \\
\hline
\end{tabular}

Source: field data, April 2016

One (1) student had the best grade which was ' $\mathrm{C} 4$ ' thus representing $2 \%$ of the sample also one (1) student had ' $\mathrm{C} 5$ ' representing $2 \%$, then grade ' $\mathrm{D} 7$ ' with frequency of 1 representing $2 \%$, followed by grade 'E8' with a frequency of 9 representing $18 \%$ and finally grade 'F9' which recorded the highest frequency of 38 representing $76 \%$ thus more than half of the sample in the experimental group failed in the pretest (Table 3 ).

The results at pretest from the experimental group showed that with class interval of $0-39$, the frequency is 38 which is the mode for the distribution. It also indicates that many students had grade F9 in the experimental group that the control group at pretest.

Table 4. Students mean value of pretest in experiment group

\begin{tabular}{lcccl}
\hline & Mean & $\mathrm{N}$ & Std. Deviation & Std. Error \\
\hline Pre-test & 29.3 & 50 & 12.698 & 1.796 \\
\hline
\end{tabular}

Table 4 shows some statistical tendencies of the pretest. The mean gave 29.3 while the standard deviation was 12.698. So the mean score of the test result shows the knowledge the students possess before the use of audiovisuals in teaching. 


\section{T-test analysis of pretest}

The results in Table 5 below indicated the data analysis between control and experimental groups of the pretest mean scores differences.

Table 5. Significant difference between control group and experimental group of the pretest of students before treatment

\begin{tabular}{lllccc}
\hline Group Test & Means & T & Df & P(2-Tailed) & Mean Difference \\
\hline Control & 33.1 & & & & \\
& & 1.4895 & 98 & 0.13955 & 3.8
\end{tabular}

Experimental $\quad 29.3$

Significance at $0.05 ; \mathrm{p}<0.05$

The control group had a mean score of 33.1 as compared to the experimental group of 29.3. The mean difference is 3.8 between the two groups (Table 5).

The research hypothesis derived from research question one, which states that there would be significant difference in between both groups (classes) on circulatory system at pretest is answered by considering results from Tables 1, 2, 3, 4 and 5 which indicated the overall scores from the pretest for both control group and experimental group. The control group had a mean score of 33.1, SD of 12.81 and SE of 1.81. The experimental group had a mean score of 29.3, SD of 12.70 and SE of 1.80. Results from the T-test analysis shown in Table 5 gives as Mean difference of 3.8, T-value of 1.49 and a P-value of 0.14 at a $95 \%$ significance level. Since the Pvalue (0.14) is greater than 0.05 we reject the hypothesis and accept the null hypothesis which implies that there is no significant difference between the control and experiment before treatment.

\subsubsection{Analysis with respect to Research Question Two.}

Research question 2: Is there any difference in post-test scores between the experimental group students who learnt with audio-visuals and control group students who learnt with the traditional method of teaching?

\section{Students marks at posttest for both control and experiment group}

The grades of the students were assigned remarks according to the GES and WAEC standard. Each raw score was also giving a weight of $5 \%$. The remarks obtained by students during the posttest are as follows:

Table 6. Group Frequency distribution of students in control group at posttest

\begin{tabular}{llccc}
\hline Marks (\%) & Grade & Remarks & Frequency & Percentage (\%) \\
\hline $0-39$ & F9 & Fail & 5 & 10 \\
$40-54$ & E8-D7 & Pass & 12 & 24 \\
$55-69$ & C6-C4 & credit & 20 & 40 \\
$70-74$ & B3 & Good & 1 & 2 \\
$75-79$ & B2 & Very Good & 5 & 10 \\
$80-100$ & A1 & Excellent & 7 & 14 \\
Total & & & $\mathbf{5 0}$ & $\mathbf{1 0 0}$ \\
\hline
\end{tabular}

Source: field data, April 2016 
Four (4) of the students failed representing $10 \%$ of the sample. Also twelve (12) students obtained the grade 'D7E8' representing $24 \%$ of the sample.

The grade 'C4-C6' recorded the highest frequency of 20 representing $40 \%$ with a remark of 'credit', The table also shows that the grade 'B3' has a frequency 1 representing $2 \%$, followed by grade 'B2' which had a frequency of 5 representing $10 \%$. The best remark obtained by students was 'excellent' which had a frequency of 7 representing $14 \%$ of the sample (Table 6).

The results also showed that majority of the students would have had passed according to the GES and WAEC grading system but also implications from the table shows that more than one-third of the sample performed poorly on the WAEC rated scale.

Table 7. Students mean value of posttest in control group

\begin{tabular}{lllll}
\hline & Mean & $\mathrm{N}$ & Std. Deviation & Std. Error \\
Posttest & 58.8 & 50 & 16.98 & 2.40 \\
\hline
\end{tabular}

Source: field data, April 2016

Table 7 shows some statistical tendencies of the posttest. The mean gave 58.8 while the standard deviation was 16.980. So the mean score of the test result shows the knowledge the students was above average or improved after they were taught using the traditional method.

According to Hatim (2011), he elaborates that enhanced learning and increased performance is not only found in the social constructivist classroom but the traditional lecture classroom can also enhance learning and increase students' performance once there is appropriate content and design of teaching or learning. Cullen et al (2004) findings also revealed in their study that there was a positive influence in students' research abilities when the traditional instructional strategy was employed.

Table 8. Group Frequency distribution of students in experiment group at posttest

\begin{tabular}{|c|c|c|c|c|}
\hline marks $\%$ & Grade & Remarks & Frequency & Percentage (\%) \\
\hline $0-39$ & F9 & Fail & 2 & 4 \\
\hline $40-54$ & E8-D7 & Pass & 4 & 8 \\
\hline $55-69$ & C6-C4 & credit & 12 & 24 \\
\hline $70-74$ & B3 & Good & 2 & 4 \\
\hline $75-79$ & B2 & Very Good & 6 & 12 \\
\hline $80-100$ & A1 & Excellent & 24 & 48 \\
\hline Total & & & 50 & 100 \\
\hline
\end{tabular}

\section{Source: field data, April 2016}

Two (2) of the students failed representing 4\% of the sample. Also four (4) students obtained the grade 'D7-E8' representing $8 \%$ of the sample. The grade 'C4-C6' recorded a frequency of 12 representing $24 \%$ with a remark of 'credit', The table also shows that the grade 'B3' has a frequency 2 representing $4 \%$, followed by grade 'B2' which had a frequency of 6 representing $12 \%$. The best remark obtained by students was 'excellent' which had the highest frequency of 24 representing $48 \%$ almost half of the sample (Table 8 ).

The results showed that majority of the students (88\%) had credit and above remarks according to the GES and WAEC grading system. 
Table 9. Students mean value of posttest in experiment group

\begin{tabular}{|c|c|c|c|c|}
\hline Mean & & $\mathrm{N}$ & Std. Deviation & Std. Error \\
\hline Posttest & 72.5 & 50 & 18.218 & 2.576 \\
\hline
\end{tabular}

\section{Source: field data, April 2016}

Table 9 shows some statistical tendencies of the posttest. The mean gave 72.5 while the standard deviation was 18.218. So the mean score of the test result shows the knowledge the students had significantly improved after they were taught using audio-visuals.

\section{T-test analysis of posttest}

With the administration of the test items, the researcher was interested in finding out whether the use audiovisuals in teaching had more effect on the performance of the students as against the traditional method of teaching. Therefore $\mathrm{T}$ - test analysis was performed on the mean scores for experimental group and control group at post-test. This was done to determine whether significant difference exist between the mean scores.

Table 10. Two sample t-test with equal variances of significant differences between control group and experimental group of the posttest

\begin{tabular}{llllll}
\hline Group Test & Means & T & Df & P(2-Tailed) & Mean Difference \\
\hline Control & 58.8 & & & & \\
& & 3.88986 & 98 & 0.000183 & \\
Experimental & 72.5 & & & & \\
\hline
\end{tabular}

Significance at $0.05 ; \mathrm{p}<0.05$

From the research hypothesis, which is that there would be significant difference in between both groups (classes) on circulatory system at post-test, results from tables 6, 7, 8, 9 and 10 indicated the overall scores from the posttest for both control group and experimental group. The control group had a mean score of 58.8, SD of 16.98 and SE of 2.40. The experimental group had a mean score of 72.5, SD of 18.22 and SE of 2.58. Results from the T-test analysis shown in Table 10 gives as a Mean difference of 13.7, T-value of 3.89 and a P-value of 0.00 at a $95 \%$ significance level. As a rule of thumb, the P-value $(0.00)$ is less than 0.05 so we accept the hypothesis and reject the null hypothesis which implies that there is no significant difference between the control and experiment after using audio-visuals in teaching the experimental group and using the Traditional method in teaching the control group.

\subsection{FINDINGS}

The purpose of the study was to find out if there was any difference in the application of the traditional method in teaching circulatory system and that of audio-visual method of teaching circulatory system in Integrated Science. Test items of 20 were administered at pretest for both control and experimental groups and post-test to find out the performance of students on the two methods of teaching being applied. Intervention activities were when the samples were taught for two weeks with both traditional method of teaching and an audio-visual method of teaching.

Two intact technical classes of fifty each of the form two students from Awe SHTS from the Kasena Nankana Municipality in the Upper East Region of Ghana was the sample used for the research. Results from pre intervention test and post intervention test intervention activity were collected, marked, recorded, analysed and discussed.

The statistical analysis of the results of the pretest of the experimental and the control groups (Tables 1, 2, 3, 4 and 5) shows that there was no statistically significant difference in the performance between the two groups at 
the beginning of the study. This reveals that the experimental and control were comparable on their understanding of the circulatory system but the statistical analysis of the post-test of the control and experimental groups (Tables 6, 7, 8, 9 and 10) showed that there was statistical significant difference in the performance between the experimental group and the control group. The experimental group performed far better than the control group in the post-test with a mean difference of $13.7 \%$. There was a significant improvement in the performance of students in the experimental group over the control group after the intervention. This means students who were taught by using audio-visuals could interpret and comprehend more the circulatory system in the study than those who were taught by the traditional method of teaching.

\subsection{Conclusion}

The use of audio-visuals in teaching produced a significant improvement in students' understanding of circulatory system as compared to the commonly instructional technique, traditionally instructional approach. Students' abilities to interpret and comprehend the concept were hugged when they were taught using audiovisuals.

Results from this study also indicated that majority of the students enjoyed the interactive lessons with audiovisuals and thus, they were motivated more to participate actively in the lessons therefore they preferred audiovisual instructional strategy to traditional strategy of instruction.

Finally, it was concluded that the use of audio-visuals in teaching was most effective way of improving student's performance in the teaching and learning of circulatory system in Integrated Science.

\subsection{Recommendations}

From the study, the following guidelines are recommended to schools and teachers who would like to include audio-visuals in the teaching and learning of Integrated Science

$>$ Science teachers should be encouraged to employ the use of audio-visuals in the delivery of their lesson so that students can perform better.

$>$ Science teachers are encouraged to improvise in the absence of real material to make their science lesson practically oriented. The ministry of education through GES and Ghana Association of Science Teachers should periodically organise workshops, in-service training frequently for science teacher on the practical use of audio-visuals in their teaching.

$>$ Science teachers are encouraged to get personal training on the use of audio- visuals that could enhance their teaching.

$>$ Head of institutions should encourage their science teachers to employ the use of audio-visuals in the delivery of their lesson.

\subsection{Areas for Further Research}

Reflecting on the findings of this study, the following recommendations are made for further research with respect to the use of audio-visuals on Integrated Science teaching:

$>$ The attitudes of SHS science teachers to the use of audio-visual method of teaching in delivering their lesson.

$>$ Use of audio-visuals by science teachers and students in improving their teaching and learning of Integrated Science.

$>$ A study should be carried out to determine the knowledge and perceptions of science teachers on the use of audio-visuals.

\section{Reference}

Anamuah-Mensah J. (2004). Enhancing the Teaching and Learning of science and technology for Nation Building. GAST conference.

Bernard, H. R., P. J. Pelto, O. Werner, J. Boster, A. K. Romney, A. Johnson, C.R. Ember \& A. Kasakoff. (1986). The construction of primary data in cultural anthropology. Current Anthropology 27: 382-396. 
Bernard, H. R. (2002). Research Methods in Anthropology: Qualitative and quantitative methods. Alta Mira Press, Walnut Creek, California.

Cresswell, J. W. (2005). Educational research: planning, conducting and evaluating quantitative research. New Jersey: Pearson Education.

Cullen, J., Richardson, S., \& O'Brien, R. (2004). Exploring the teaching potential of empirically-based case studies. Accounting Education, 13(2), 251-266.

Davis, B. (1993). Tools for teaching. San Francisco: Jossey-Bass

Felder, R. (1993). Reaching the second Tier: Learning and Teaching styles in college science education.Journal of college science Teaching, 23(5), 286-290.

Graham, C. (1976). The history of Education in Ghana. Accra: Ghana Publishing Cooperation.

Gregory, R.J. (1992) Psychological Testing: History, Principles and Applications, Allyn and Bacon: Boston.

Hatim, A. (2011). A comparison of cooperative learning and traditional lecture methods in the project management department of a tertiary level institution in Trinidad and Tobago. Caribbean Teaching Scholar, 1 (1), 49-64

Jadal, M. (2011). A Study of effectiveness of the Audio-Visual aids in Teaching and Learning of English at Primary Level in Z.P. Primary Schools of Solapur District, Volume - I, Issue VII.

Mckeanchie, W. J. (1994). Teaching tips: A guidebook for the beginning college teacher. Lexington Mass, DC: Health \& Co.

Otto, J. \& Towle, A. (1985). Modern Biology. New York: Holt, Rinehart and Wiston.

Samreen Akram et al (2012). Use of audio visual aids for effective teaching of biology at secondary schools level. Elixir Leadership Mgmt. 50 (2012) 10597-10605

Shri, K. M., \& Badri, Y. (2014). Audio-visual aids \& The secondary school Teaching. Global Journal of Human-social science: G Linguistics \& Education. Vol. 14 issue 1 version 1, 6-7

WAEC (2011).Chief examiners report on Biology. Lagos: WAEC Press. 